\title{
SVN \\ Hand in hand with the world to conquer stroke
}

\author{
Yongjun Wang, ${ }^{1}$ David Wang ${ }^{2}$
}

To cite: Wang $Y$, Wang $D$. Hand in hand with the world to conquer stroke. Stroke and Vascular Neurology 2016;1: e000007. doi:10.1136/svn2016-000007

Received 4 January 2016 Accepted 8 January 2016

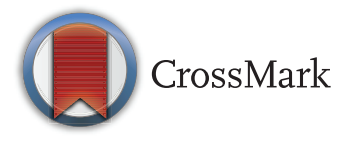

${ }^{1}$ Department of Neurology, Beijing Tiantan Hospital, Beijing, China

${ }^{2}$ Chinese Stroke Assoication, Beijing, China

Correspondence to Professor Yongjun Wang; yongjunwang1962@gmail. com
Stroke is a major problem that threatens the health of mankind. In countries with lowlevel or mid-level income, stroke is an even more serious problem. ${ }^{1}$ In some countries, such as in China, stroke has become the leading cause of death. Indeed, stroke continues to disable people and destroy lives. However, the battle of fighting strokes has never stopped. Many have fought hard in the past. $^{2}$

In 1543, Italian scholar Andreas Vaslius described the anatomy of cerebral circulation for the first time. That opened a window for people to explore the mystery of cerebral vasculature. In 1681, English scholar Thomas Willis described the circulatory connections at the skull base that was named after him: the circle of Willis. ${ }^{3}$ People have been able to gain more in-depth knowledge of brain anatomy since. In 1658, German scholar Johann Jacobus Wepfer published the first book on stroke, the Apoplexia, which was the earliest systematic and theoretical description of cerebrovascular disease. With a series of landmark discoveries thereafter, the Europeans led the world in this field for over 400 years. It was not until after World War II that the prominence of academic work in cerebrovascular diseases crossed the Atlantic and stayed in the USA ever since.

On the basis of the contents and field of exploration, the history of cerebrovascular disease can be divided into three important historical phases: from the 16th to 18th century, the descriptive phase of the cerebrovascular anatomy, physiology and pathology; from the 19th century to the 1960s of the 20th century, the discovery phase of new technology in the diagnosis and treatment of cerebrovascular diseases; after the 1970s of the 20th century, the dawn of multicentre clinical trials, marking the beginning of evidence-based medicine (EBM).

EBM has brought unprecedented hope to the war against stroke. Results from many large, multi-international centre, prospective and randomised comparative trials (RCTs) have contributed to the building of a solid foundation for the current clinical practice of stroke. Some of the examples of these RCTs include carotid artery endarterectomy, carotid artery angioplasty and stenting, mono and dual antiplatelet therapies, intravenous thrombolysis and intra-arterial thrombectomy, stroke unit, etc. These multicentre research projects have given new meaning to stroke prevention and treatment. Therefore, to a great extent, EBM symbolised the arrival of international collaboration. Multi-international clinical trials have become a sign of the times showing that the world could work together to protect our population from the injury of stroke.

In 2015, medical practice has entered into a new phase of precision medicine. Studies of genomics have been implemented into day-to-day stroke therapies. Pharmacogenomics and protein genomics have opened up new opportunities for personalised stroke therapies. The time of precision stroke therapy has arrived in an unannounced fashion.

While EMB seeks a common strategy to prevent or treat a condition in different populations, precision medicine would treat each patient by relying on the biological difference in each individual. That is why research on therapies based on ethnic differences is now a hot topic. ${ }^{4}$

Stroke is different between the East and the West. Compared to the Caucasians, Asians have more intracerebral haemorrhages. On the causes of ischaemic stroke, Asians have more intracranial arteriopathy while Caucasians have more carotid diseases. There are also significant pharmacogenomic differences between the East and the West. For example, on the issue of clopidogrel metabolism, Asians or Chinese carry two loss-of-function variant alleles and are classified as 'poor metabolisers' due to having little or no CYP2C19 enzyme activity. ${ }^{5}$ We have certainly learnt that patients would be placed at risk if given a treatment that has only been studied well in a different ethnic population. Therefore, it is about time for us to put our resources together, regardless of 
our ethnic background or cultural difference, to continue to explore genomic or pharmacogenomic differences in stroke therapy.

The Chinese Stroke Association (CSA) was officially established on 19 January 2015. The formation of this national disease-specific association is very significant for the country since China has the most number of patients with stroke. In an effort to fight stroke together and unite the talent from China, North America, Australia, Europe and the world, CSA's official English journal Stroke and Vascular Neurology (SVN) has been born. We hope that SVN can record our effort in conquering stroke and offering guidance in stroke clinical practice.

Developing international partnership and hand in hand with the world to conquer stroke; this is what SVN is all about!

Competing interests None declared.
Provenance and peer review Commissioned; internally peer reviewed.

Open Access This is an Open Access article distributed in accordance with the Creative Commons Attribution Non Commercial (CC BY-NC 4.0) license, which permits others to distribute, remix, adapt, build upon this work noncommercially, and license their derivative works on different terms, provided the original work is properly cited and the use is non-commercial. See: http:// creativecommons.org/licenses/by-nc/4.0/

\section{REFERENCES}

1. Mensah GA, Norrving B, Feigin VL. The Global Burden of Stroke. Neuroepidemiology 2015;45:143-5.

2. Kim AS, Cahill E, Cheng NT. Global Stroke Belt: Geographic Variation in Stroke Burden Worldwide. Stroke 2015;46:3564-70.

3. Williams AN. Thomas Willis' understanding of cerebrovascular disorders. J Stroke Cerebovasc Dis 2003;12:280-4.

4. Nakagawa K, Vento MA, Ing MM, et al. Racial disparities in methamphetamine-associated intracerebral hemorrhage. Neurology 2015;84:995-1001.

5. Chan A, Pirmohamed M, Comabella M. Pharmacogenomics in neurology: current state and future steps. Ann Neurol 2011;70:684-97. 